\title{
A critical juncture in universal healthcare: insights from South Korea's COVID-19 experience for the United Kingdom to consider
}

\author{
Kyungmoo Heo (i) ${ }^{1}$, Keonyeong Jeong (i) ${ }^{1}$, Daejoong Lee (i) ${ }^{2} \&$ Yongseok Seo (iD) ${ }^{1 \times}$
}

Universal healthcare systems have undergone a severe stress test in the form of the ongoing COVID-19 pandemic. With respect to the system-embedded allocation of decision-making powers and responsibilities among actors, different modalities have been revealed in the COVID-19 responses of South Korea and the UK, respectively. This article compares and analyzes how these two countries' healthcare systems have reacted to COVID-19. Although both have implemented similar responsive measures, the UK has recorded a higher number of confirmed cases per thousand people and a higher death rate. Based on the analysis on which this paper is built, the key differences between the two systems are the UK system's lack of: (1) appropriate medical equipment and technologies along with the human resources; and (2) flexible policy options to incentivize healthcare providers and induce cooperation from the public in a time of national crisis. The UK's healthcare system is now approaching a critical juncture. The expansion of internal competition, which was introduced to the system in 1991, can serve as means of initiating a resolution to the above-mentioned issues and further reform its system. Under the UK government's close supervision and precise control, allowing non-reimbursable special medical treatment in the system and widening public choice of medical services would be a suitable policy approach promoting internal competition while at the same time maintaining the UK's devotion to universal healthcare. The underlying implication of internal competition though is the sharing of decision-making powers and responsibilities with societal and private sectors by inducing and facilitating participation at all levels. Fighting against COVID-19 however is widely considered 'all-outwar.' Under the UK government's supervision and control, it is time for society to step up and fight the pandemic together.

\footnotetext{
${ }^{1}$ Moon Soul Graduate School of Future Strategy, Korea Advanced Institute of Science and Technology (KAIST), Daejeon, Republic of Korea. ${ }^{2}$ Development Finance Division, Korea Ministry of Economy and Finance, Daejeon, Republic of Korea. ${ }^{\circledR e m a i l: ~ m a n o a @ k a i s t . a c . k r ~}$
} 


\section{Introduction}

he healthcare systems of both South Korea (hereinafter Korea) and the United Kingdom (UK) pursue universal healthcare, whereby everyone can access healthcare services with a minimal financial burden (United Nations, 1948; World Health Organization, 1978). The main difference between the two is that the UK's healthcare system directly procures resources for healthcare services while Korea's system takes advantage of the efficiency of the private sector, using an intermediate mechanism called "public insurance" (Böhm et al., 2013; Navarro, 1989). In other words, in the UK, it is a state actor who makes decisions on policy, finance, and services. However, in Korea, under government supervision, a customer (patient) participates in decision-making, meaning essentially that it is a societal actor who manages finance, while a private party provides the given healthcare service(s).

The COVID-19 pandemic, however, undermines this vision of universal healthcare. It is the first moment in modern history that all nations' healthcare systems have come under similarly severe stress tests. While COVID-19 is unquestionably a terrible crisis, it does present a useful opportunity for countries to learn from one another and fill any gaps that have long lingered in their healthcare systems.

To tackle COVID-19, many governments have designed and implemented a wide range of policy measures. In particular, the universal healthcare system of Korea has received wide recognition for its success in flattening the curve of confirmed COVID19 cases (Majeed et al., 2020; Lee et al., 2020; Heo et al., 2020; Park et al., 2020; Shim et al., 2020). The purpose of this comparative research is to analyze how two public healthcare systems (those of Korea and the UK) have reacted to COVID-19. Taking the healthcare systems of both countries as institutions, this comparative case research presents insights to boost the further development of the UK's healthcare system.

\section{Theoretical framework and methods}

Historical institutionalism is a theory whereby once a single institution is formed, its original attributes tend to persist over time. However, when an institution meets a 'critical juncture,' the original path of institutional development can be deviated from (Capoccia and Kelemen, 2007; Fougere, 2001; Thelen, 1999). Based on this theoretical framework, each institution can evolve at a critical juncture from its long-established historical, social, and cultural attributes. Based on a large number of daily confirmed cases and high casualty rates along with its other heavy global impacts, we assume that COVID-19 represents a critical juncture for any universal healthcare system. To cope with the pandemic, it is necessary to explore novel approaches, conduct a comparative analysis of countries' systems, and identify preliminary indications of successful and failed approaches.

Taking into account Esping-Anderson's research approach of applying institutional comparison between countries (1990), this article uses a strategic case-study in which two different countries and their national healthcare systems are compared. Its aim is to sharply summarize the differences in historical and institutional circumstances of the respective countries' systems by extracting some relevant and representative examples (Ragin, 2014; Ragin and Amoroso, 2011; Kümpers et al., 2005; Scharpf, 2000). In this way, a strategic case-study-based comparison can answer detailed inquiries "examining a relevant issue or reveals phenomena through the process of examining the entities within its social and cultural context" (Salkind, 2010, p. 115).

This article utilizes the comparative study process devised by Janoski and Hicks (1994, pp. 8-9). Following this process, we first explored the problem of our research subject from the preceding body of work on historical institutionalism and critical junctures (Capoccia and Kelemen, 2007; Fougere, 2001; Thelen, 1999). Thereafter, the healthcare systems of both Korea and the UK were taken as comparable institutions in their responses to COVID-19 from March 2020 to June 2020, with data and information collected based on the pre-framed architecture and its selected variables of interest. In particular, variables were selected on account of the success factors mentioned by the Korean authorities (please refer to the first column of Table 2). Lastly, we analyzed the similarities and differences between the two institutions and drew an inductive conclusion of this two-nation comparison.

In an institutional case comparison, as the number of cases reduces, qualitative methods are more commonly applied (Ragin, 2014; Ragin and Amoroso, 2011). Based on practice-oriented observations and field experiences, we then utilized gray literature to gather relevant data and information such as materials and reports produced by organizations (e.g., governments) outside of the traditional academic publishing and distribution channels (Garousi et al., 2016). A gray literature review can be the most appropriate method to inspire and share early and preliminary lessons emerging from the public administration and policy communities directly related to this global crisis. This method's utility has been proven, and it is used by many researchers in various academic domains such as medicine and healthcare (Favin et al., 2012; Van Cauwenberghe et al., 2010), software engineering (Garousi et al., 2016; Soldani et al., 2018), and library and information studies (Farace and Schöpfel, 2010; Stempfhuber et al., 2008). In this article, to minimize any risk of little or no scientific factual representation of data or analyses (Farace and Schöpfel, 2010), the formal reports and official website materials of both governments were used as data and information sources. Moreover, to maximize the research's validity, we follow Petersen's systematic approach of the gray literature review (Petersen et al., 2008; Mahood et al., 2014), ranging from first exploiting general web search engines, employing "saturation" as the stopping criteria, to then combining inclusion/exclusion criteria with quality assessment control factors.

\section{Result}

Institutional similarities and differences between Korea and the UK. Both Korea and the UK have comprehensive and universal healthcare systems. Under these systems, all inhabitants receive the same healthcare services and benefits provided by their governments either indirectly or directly at a minimum cost or no cost. First, the UK's healthcare system established in 1948 by the National Health Service Act (1946) is the largest public healthcare system in the world (Battilana, 2011; Davie and Nutley, 2000). The system runs on a budget of approximately USD 170 billion per year and employs more than one-and-a-half million people as of 2020. Under this system, the UK government directly provides health, medical and welfare services to all of its inhabitants. Meanwhile, the Korean healthcare system is designed to protect its inhabitants by sharing the burden of unexpected risks from disease among inhabitants and the Korean government, known as the principle of social joint responsibility (The Government of the Republic of Korea, 2020a). Since the introduction of the system in 1963, it has operated as a kind of social insurance policy for more than 50 million subscribers (Kwon, 2008; Yoon, 2020). The Korean Ministry of Health and Welfare's budget for health insurance covers approximately $20 \%$ of the estimated amount of insurance premiums for each year. This subsidy allows Korea to maintain the national healthcare system 
and guarantee a universal healthcare service for all of its inhabitants.

The working mechanisms of the healthcare systems of both Korea and the UK are different in a few respects. In the UK, healthcare is factored into each inhabitant's tax liabilities, and the UK government provides services directly through publiclyowned healthcare providers. Minors, senior citizens, and lowincome families receive services free of charge, and even ordinary inhabitants pay around one percent of the total cost. Similar to the UK, the inhabitants of Korea also pay a certain fee, known as an insurance premium (based on their wealth and income) to the public agency, the National Health Insurance Service. This premium operates like a form of taxation. Moreover, Korea's system has a unique feature, namely the mandatory inclusion of private healthcare providers in the national healthcare scheme. In Korea, public healthcare providers are scarce. Accordingly, private providers can carry out public duties. For example, if a patient goes to a hospital and receives treatment, a significant portion of the hospital costs will be reimbursed by the Korean healthcare system. This results in the patient shouldering a low burden with respect to hospital costs. Table 1 below outlines the features of the healthcare systems of both Korea and the UK based on the criteria relevant to the purposes of this research.

As seen in the table above, the differences between the two systems are significant in the category of medical equipment and technologies, as well as human resources to be able to handle them. For instance, the number of computed tomography (CT), extracorporeal membrane oxygenation (ECMO), magnetic resonance imaging (MRI), and mechanical invasive ventilators in Korea outnumber those in the UK. Moreover, as of 2017, the clinical radiology workforce of Korea was eight times larger than that of the UK (3656 for the UK vs. 23,998 for Korea) despite the UK having nearly double the amount of health and social care employees of Korea (Shin et al., 2018; The Royal College of Radiologists, 2020).

There is no doubt that the reverse transcription-polymerase chain reaction (RT-PCR) test is the most accurate means of confirming a COVID-19 case/diagnosis. However, at the early stage of the pandemic, CT and MRI tests, and ECMO treatment, were essential and effective in pre-testing a large number of patients and handling a sudden outbreak of an unknown disease. First, an initial chest CT scan is used as an early diagnosis of the viral disease (Fang et al., 2020). It evaluates the lung abnormalities, with observed imaging patterns on chest radiography and computed tomography, that are normally detected in COVID-19 (Bernheim et al., 2020). Second, an MRI scan tracks the development of COVID-19 symptoms. A patient with a severe bout of COVID-19 shows neurologic manifestations associated with MRI scans of abnormal brains (Poyiadji et al., 2020; Kremer et al., 2020) along with symptoms of anosmia, partial loss of sense of smell, or changes in taste (Aragão, et al., 2020; AlKetbi et al., 2020). Third, ECMO treatment is a process that supports someone who is undergoing respiratory failure (Royal Papworth Hospital, 2020; Alom et al., 2020). As a last resort for COVID-19 care, the ECMO treatment allows the organs to rest and recover.

CT and MRI tests, and ECMO treatment, have been important elements of care in the pandemic. Meanwhile, the disinfection of the environments around CT and MRI tests, and ECMO treatment, and the necessary human resources should not be

Table 1 Institutional comparison between healthcare systems of both South Korea and the UK.

\begin{tabular}{|c|c|}
\hline \multicolumn{2}{|l|}{ Aspects } \\
\hline Government health system & National Health Insurance \\
\hline $\begin{array}{l}\text { Government health insurance in total } \\
\text { health care }\end{array}$ & $100 \%$ of total population (2017) \\
\hline Beds in publicly owned hospitals & $10 \%(64,385$ out of 631,092 hospital beds (2017)) \\
\hline Number of critical care beds & 10.6 (per 100,000 inhabitants) \\
\hline Medical equipment $\&$ radiology & . CT scanners: 36.85 per million population (2014) \\
\hline workforce (relevant to respiratory or & - MRI units: 25.5 per million population (2014) \\
\hline infectious disease) & ECMO beds: 350 (March 2020) \\
\hline & - Mechanical invasive ventilators: 9823 (March 2020) \\
\hline & $\begin{array}{l}\text { Negative pressure isolation rooms (beds): } 755 \text { rooms } \\
\text { (1027 beds) }\end{array}$ \\
\hline & Clinical radiology workforce: 3656 (2017) \\
\hline Total health and social employment & 37.35 per 1000 inhabitants \\
\hline Medical service & Indirect provision through private hospitals \\
\hline
\end{tabular}

Health insurance fee rate and benefit Rate: $6-8.5 \%$ of income/wealth

All inhabitants receive the same benefit.

Foreigners: same as above but minimum USD 89.31 (the rate as of 18 May 2020)

The United Kingdom ${ }^{a}$

National Health Service
$100 \%$ of total population (2017)

$100 \%(167,589$ out of 167,589 hospital beds (2017))

6.6 (per 100,000 inhabitants)

CT scanners: 9.46 per million population (2014) MRI units: 7.23 per million population (2014) ECMO beds: 15 from five providers (Feb 2020) Mechanical invasive ventilators: 10,900 (April 2020)

Negative pressure isolation rooms (beds): $n / a$ Clinical radiology workforce: 23,998 (2017) 59.78 per 1000 inhabitants

Direct provision from government and public hospitals

No additional fee for health (embedded in government tax)

Health fee: $19.9 \%$ of income tax (inhabitants have a $20-45 \%$ income tax band)

Foreigners: an immigration health surcharge of USD 362/year or USD 484/year (the rate as of 18 May 2020)

Insurance coverage and non-

Coverage: $63.8 \%$ of the total medical cost (2018) reimbursable special medical A patient also has a free option whether to choose the non-reimbursable special medical treatment which is not covered by the system.

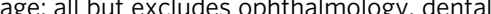
care, prescription drugs, long-term care services No non-reimbursable special medical treatment exists within the system.

${ }^{*} \mathrm{CT}$ computed tomography, ECMO extracorporeal membrane oxygenation, MRI magnetic resonance imaging, USD United States Dollar.

${ }^{*} C T$ computed tomography, ECMO extracorporeal membrane oxygenation, MRI magnetic resonance imaging
${ }^{*}$ Exchange Rates: 1 Korean Won $=$ USD 0.00082, 1 United Kingdom Pound = USD 1.29 (28 July 2020).

a Data collected from (1) OECD Health Statistics 2019 (https://www.oecd.org/health/health-data.htm), (2) Statista Coronavirus (COVID-19) disease pandemic- Statistics and Facts (https://www. statista.com/topics/5994/the-coronavirus-disease-covid-19-outbreak/), (3) GOV.UK website (https://www.gov.uk/coronavirus), (4) Coronavirus Disease-19, Republic of Korea website (http://ncov. mohw.go.kr/en/) (Accessed on 28 July 2020). 
neglected at any time, but particularly amid an outbreak of a contagious viral disease. All necessary disinfection measures should be applied in CT and MRI scans and in ECMO treatment when confirming (or disconfirming) COVID-19 cases. Naturally, $\mathrm{CT}$ and MRI rooms have positive air pressure, forcing the bulk of the air out of the MRI area without allowing it to circulate back into the room based upon standard designs (Kooraki et al., 2020). Adversely, an ECMO room (or bed) has negative air pressure, with the air pressure dropping below that of outside, so air cannot escape outside (Royal Papworth Hospital, 2020; Alom et al., 2020). Moreover, the human resources needed to handle technological equipment should also be kept safe from infection. In a pandemic situation, all clinical radiologists and nurses have to wear personal protective gear. For example, during the Severe Acute Respiratory Syndrome in 2003 and the Middle East Respiratory Syndrome Coronavirus in 2015, Korea learned to be wary of in-hospital infections (Heo et al., 2020). Learning lessons from these previous outbreaks, during the COVID-19 crisis, Korean hospitals have been separating treatment processes for respiratory patients from those of non-respiratory patients to minimize virus transmission. Second, the Korean healthcare authorities have been conducting a daily test of all medical personnel (including equipment operators) and sanitizing each piece of equipment.

The UK is currently struggling to administer a sufficient number of CT and MRI tests, as well as ECMO treatments. On account of the impact of COVID-19, more than half of people needing CT and/or MRI tests faced at least a six-week wait as of April (almost 50,000 patients were waiting for a CT scan, and 80,000 patients were waiting for an MRI scan) (Ashworth, 2020). The demand for CT and MRI among patients exhibiting COVID19 symptoms was exceptional; ordinary patients had to wait for potentially life-saving tests while NHS personnel, as well as care staff at the frontline of the COVID-19 response, were also not being adequately tested. During the COVID-19 pandemic, the number of ECMO rooms (or beds) has remained limited, while the demand for them increased dramatically (Royal Papworth Hospital, 2020). For example, the ECMO capacity of Royal Papworth Hospital NHS Foundation Trust's critical care unit is nine at any single point but this had to be increased temporarily to 19-34 as it was the subject of 190 online referrals at the end of April (Royal Papworth Hospital, 2020). In addition, the UK has also faced difficulty in expanding the necessary human resources to conduct CT and MRI tests, as well as administer ECMO treatment, because training and education are time-consuming. For example, the operation of CT and MRI scans requires a license (e.g., clinical radiologist), and the administering of ECMO treatment demands highly-specialized skills.

Policy measures of Korea and the UK in tackling COVID-19. Both countries have implemented various policy measures to tackle COVID-19. Rather than analyzing their overall responses to COVID-19, however, this part narrows it down to the impacts of both countries' policies on health, medical and welfare aspects. By introducing six success factors in the Korean healthcare system's handling of COVID-19 (Lee et al., 2020; Yoon, 2020), we observe and compare how both countries performed with regard to these variables. Table 2 below explains the detailed roles and policy measures of both countries.

Deduction of health and medical fees. Both countries offer healthcare discounts. Korea subsidizes insurance premiums by 30 to $50 \%$ of the total fee for those who register in special disaster areas and whose incomes are lower than the national average (The Government of the Republic of Korea, 2020a). In the UK, because health and medical fees are included in general taxation and the National Insurance (NI) payment, the UK government provides relief through the local council tax support scheme (Jenrick, 2020), a deferral of taxes under 'time to pay arrangements' (HM Revenue and Customs, 2020), and subsidies for NI payments (Department for Business, 2020).

Financial and material support for COVID-19-afflicted inhabitants (including those self-isolated). Despite administrative differences in the volume of recipients of state support, both countries have financially supported confirmed COVID-19 patients and self-isolated individuals. In particular, the Korean government introduced diverse financial and material support options because its healthcare system had the flexibility to change the size and composition of insurance schemes. For example, the Korean government-subsidized public masks (which filter out at least $95 \%$ of airborne particles) while limiting the number of masks that could be purchased by a single person (three masks per week) (The Government of the Republic of Korea, 2020b). Moreover, Korea provided basic income support to each Korean citizen based on their economic status and financial situation within two months of the country's COVID-19 peak. As the insurance premiums are levied based on the individual income and wealth of individuals, the extent of the premium determined the extent of COVID-19 relief provided.

Support and incentives for healthcare providers. Healthcare providers in Korea and the UK both receive financial and administrative support from their respective governments. The Korean healthcare system incentivizes providers with monetary support because most of them are independent and private hospitals. By enacting the Health Insurance Benefit Expense Early Payment Special Decree, the Korean government has supported providers experiencing financial difficulties due to a decrease in patients (The Government of the Republic of Korea, 2020a). Providers were allowed to freely spend these monetary benefits at their discretion, with many using it to pay hospital rental fees. Meanwhile, the UK had an advantage when it came to supporting the providers more directly because of its direct government control over them. For example, unlike in Korea, the UK can intervene in the contractual process of medical procurement to relieve the burden of public healthcare providers. For healthcare practitioners who experience a decrease in patients, the UK government guarantees their wages.

Testing, diagnosis, and treatment. Neither Korea nor the UK charges for treatment. However, unlike the UK, Korea does charge a small fee for the testing and diagnosis of an asymptomatic patient (30-60\% of total medical expenses); approximately USD 19.6 to USD 40.4 (The Government of the Republic of Korea, 2020b). In Korea, unlike the UK, inhabitants must make an 'out-of-pocket' payment for all treatment (less than 4 USD per first private clinic visit for signs and symptoms). In other words, they bear a certain portion of the treatment cost, other than the amount covered by insurance. The rationale behind this policy is to encourage responsible behavior on the part of inhabitants, and this also applied to the country's fight against COVID-19 as it managed to induce cooperation from the public.

Bereavement support (including funeral costs). Adhering to a similar rationale to that applied in testing, diagnosis, and treatment, both countries to some degree cover the bereavement and funeral costs of those dying from COVID-19. Both governments consider that adequate handling of dead bodies is another means of limiting the spread of COVID-19. 
Table 2 Comparison of Healthcare Measures in South Korea and the UK in tackling COVID-19.

Countries

Measures

Deduction of health and

medical fees

Financial and material support

(including self-isolated

inhabitants)

Support and incentives for

healthcare providers

Testing, diagnosis, and treatment for free (or minimum charge)

Bereavement support (including funeral costs)

Information sharing through the central patient record

checking system

\section{South Korea ${ }^{a}$}

Insurance premium support to subscribers

. $50 \%$ reduction in insurance fee for inhabitants registered in a special disaster area and whose income is lower than $50 \%$ of the national average between March and April 2020

-30-50\% reduction in insurance fee for Koreans whose income is lower than $40 \%$ of the national average for three months (approximately 11,600,000 people, USD 73 per person)

Financial support to a confirmed patient and the selfisolated

- Employed: paid leave (max. USD 107 per week)

- Individuals other than employed (ex. self-employed): monthly USD 373 to USD 1195 per household (depends on the number of a house member)

Masks for the public (the price of public masks: USD 1.2 per item)

- Mask which filter at least 95\% of airborne particles - Subsidized by the government (but not by the system). The government started feasibility studies on masks in the healthcare insurance coverage on March 2020

Insurance fee as a standard for government subsidies - Because the system is levied by income and wealth, it becomes standard for "central universal basic income" and local "emergency disaster relief money" for those who need it most.

- Early payment to hospitals: approximately USD 70.6 billion by enacting the Health Insurance Benefit Expense Early Payment Special Decree (as of 14 May 2020)

- Advance payment for financially struggling hospitals: the amount of loss that is the average of last the three months

- Shortening of the insurance review process:

Maximum 10 days from maximum 20 days for quick expense payment

Testing and diagnosis: patient dependent

- Symptomatic patient: no charge (copay of $36 \%$ of primary care)

- Asymptomatic patient: 30 to $60 \%$ of total medical expenses, approximately USD 19.6 to USD 40.4 depending on the level of the hospital (copay of $36 \%$ of primary care)

Treatment: no charge for all

- For citizens: $80 \%$ from insurance $+20 \%$ from government

- For foreigners: $100 \%$ from government

Financial support to medical providers, funeral services, cremation facilities: USD 2460 per person

- Under the newly enacted national funeral care guidelines

Funeral expenses for bereaved families: USD 8200

- Average funeral expenses: USD 9840 - USD 13,120

- Personal health and medical information provided by the Health Insurance Review and Assessment Service $\checkmark$ Real-time provision of patient information along with information on any chronic or underlying diseases

\section{The United Kingdoma}

Tax and National Insurance relief

USD 610 million hardship fund of council tax relief to vulnerable people and households through the Local Council Tax Support scheme

Deferral of certain VAT and income tax payments under 'time to pay arrangements'

Supports National Insurance contributions under the coronavirus job retention scheme

Statutory sick pay to a confirmed patient or the selfisolated

Employed: USD 115 per week (paid by an employer for up to 28 weeks)

Individuals other than employed (ex. self-employed): Universal Credit (e.g., Child Tax Credit, Housing Benefit, Income Support, income-based Jobseeker's Allowance, income-related Employment, and Support Allowance, and Working Tax Credit) based on their household income, rent fee, number of children, etc.

No subsidies in masks (a price of a mask in the UK: USD 9.67)

Block-buy of capacity in independent (private) hospitals Guarantee and protection of GPs' income if other routine contracted work needs to be substituted Additional funding to providers for covering extra costs in responding to the COVID-19 emergency

Minimum burden of formal contract documentation and contract management processes

- Canceling all routine CQC inspections

Testing, diagnosis, and treatment: no charge for either symptomatic patients or asymptomatic patients - If patients start treatment and a test then shows they do not have COVID-19, they may be charged for any treatment after getting the test result.

Financial support from the government

USD 854 if the person died before 8 April 2020

USD 1220 if the person died on or after 8 April 2020

Average funeral expenses in the UK: USD 4867

Electronic Health Record systems in the

healthcare system

The systems are run by NHS Digital that functions as a center for sharing a patient's information such as GP records, summary care records, etc.

COVID-19 Coronavirus Disease, CQC care quality commission, GP general practitioner, NHS National Health System, USD United States Dollar, VAT value added tax.

${ }^{*}$ Exchange Rates: 1 Korean Won $=$ USD 0.00082, 1 United Kingdom Pound = USD 1.29 (28 July 2020).

a Data collected from (1) OECD Health Statistics 2019 (https://www.oecd.org/health/health-data.htm), (2) Statista Coronavirus (COVID-19) disease pandemic- Statistics and Facts (https://www. statista.com/topics/5994/the-coronavirus-disease-covid-19-outbreak/), (3) GOV.UK website (https://www.gov.uk/coronavirus), (4) Coronavirus Disease-19, Republic of Korea website (http://ncov. mohw.go.kr/en/) (Accessed on 28 July 2020). 
Table 3 COVID-19 confirmed cases and death in the UK and South Korea.

\begin{tabular}{|c|c|c|}
\hline Countries Aspect & UK & South Korea \\
\hline Population (thousand)a & 66,436 & 51,635 \\
\hline Population densityb & 275 & 529 \\
\hline Confirmed cases $^{\mathrm{C}}$ & 300,111 & 14,203 \\
\hline Deaths $^{3}$ & 45,759 & 300 \\
\hline $\begin{array}{l}\text { Cases per thousand } \\
\text { Populations }\end{array}$ & 4.51 & 0.27 \\
\hline Death Rates (death/cases) & $15 \%$ & $2 \%$ \\
\hline \multicolumn{3}{|c|}{$\begin{array}{l}\text { aData collected from } 2018 \text { Population (indicator) from OECD (https://data.oecd.org/pop/ } \\
\text { population.htm) (Accessed on } 25 \text { June 2020). } \\
\text { bData collected from } 2018 \text { Population Density (people per sq. km of land area) from World Bank } \\
\text { (https://data.worldbank.org/indicator/EN.POP.DNST) (Accessed on } 25 \text { June, 2020). } \\
\text { cData collected from } 2020 \text { COVID-19 Worldometer (https://www.worldometers.info/ } \\
\text { coronavirus/) (Accessed on } 28 \text { July, 2020). }\end{array}$} \\
\hline
\end{tabular}

Information-sharing through a central patient-record-checking system. As Korea and the UK run public healthcare programs, patients' medical histories are recorded and utilized in a centralized manner. This means that both countries make use of personal information in their treatment of COVID-19, including a patient's history of chronic and underlying diseases.

To sum up, the healthcare systems in both countries are deeply rooted in the philosophy of universal healthcare provision. Indeed, courtesy of their institutional similarities, the UK and Korea have implemented policy measures in similar ways to tackle COVID-19. However, there are differences to note between them as well. As of 28 July 2020, the UK had had 300,111 confirmed cases and 45,759 deaths, while Korea had had only 14,203 cases and 300 deaths (Worldometers, 2020). Clearly, despite the above-mentioned similarities in terms of universal healthcare coverage, the effect of COVID-19 has been far graver in the UK than in Korea. Table 3 below outlines the number of COVID-19 cases per thousand of population and the death rates in both countries (Worldometers, 2020).

\section{Discussion}

Looking at the results presented in the table above, key differences between the two systems remain in the following: (1) appropriate medical equipment and technologies along with the necessary human resources to respond to the sudden pandemic; and (2) flexible policy options incentivizing healthcare providers and inducing cooperation from the public in a time of national crisis.

With this in mind, this article proposes that through government control and supervision, the expansion of internal competition introduced to the UK system in 1991 can serve as a means of initiating a resolution to the above-mentioned issues, using this critical juncture (COVID-19) as a moment to reform the system. The following paragraphs present two approaches: (1) allowing non-reimbursable special medical treatment in the healthcare system; and (2) giving the public an open choice of medical services (both of which have been effectively utilized in Korea during its response to COVID-19). These approaches could be applied to the UK's healthcare system while not undermining any foundations of the UK's universal healthcare objectives. Thorough supervision and precise control of a healthcare authority is a critical foundation though, making sure that, for the sake of the patients, services do not become too competitive. Without a government's strong control, internal competition may lead to a situation where only the rich can access standard treatment. Nevertheless, the UK can share decision-making power between societal and private sectors while strengthening the vision of the UK's universal health coverage.
Before delving into these approaches, it is necessary to clarify the causal relationship between expanding internal competition and quality of response to COVID-19. It has been shown that internal competition can be effective in situations of sudden uncertainty and complexity in various ways (Birkinshaw, 2001; Propper et al., 2004; Xavier, 2003). First, internal competition creates flexibility. The future is of course uncertain but by facilitating different channels and diverse approaches, a flexible mechanism, system, and/or an organization can respond rapidly to uncertain political, societal, and technological changes. Second, internal competition has the power to change the status quo. For times of sudden external threat, when a revolutionary measure is required, internal competition can change old and traditional inertia-ridden systems. According to Birkinshaw, internal competition "provides an antidote for myopic thinking, essentially as a means of challenging the hidden assumptions" that underpin a system (Birkinshaw, 2001, p. 22). Third, when an external threat emerges, the internal competition provides strong motivation to fight back among the involved actors. Their internal competitiveness can lead to coordinated efforts to combat a sudden external threat. Such actors in such circumstances tend to pull together and work harder. Therefore, internal competition's advantages may enable direct but flexible government action with respect to health and medical measures at the early stage of an infectious disease's development, including early case-finding, quarantining of contacts, testing, epidemical investigation, and border control (Heo et al., 2020). In that sense, internal competition is essential to delivering a better response to a pandemic as long as it is kept under control by a reliable authority such as a government.

Meanwhile, referring back to the two Korean approaches that may be applicable to the UK, the first of these would be the introduction of non-reimbursable (i.e., not covered by the UK's healthcare system) special medical treatment as part of the daily medical services, under the government's thorough supervision and precise control, in order to expand the degree of internal competition within the system. As patients pay an additional 'outof-pocket' expense for choosing to receive these treatments, healthcare providers compete with each other to offer better services. Pertinently, by shifting certain health services and medical treatments from its original service coverage to non-reimbursable items, the UK could have flexible policy options in place to effectively respond to a national healthcare crisis. For example, in such instances, Korea immediately includes non-reimbursable items into national coverage such as testing, diagnosis, and the treatment of infectious diseases. By varying their coverage between symptomatic and asymptomatic patients, Korea can also fully provide universal healthcare only to those who are sick while encouraging responsible behavior on the part of inhabitants to mitigate the risk of possible infection. In addition, the inclusion of subsidized public masks in the healthcare scheme is another example of Korea's policy flexibility. Meanwhile, the additional 'out-of-pocket' money for non-reimbursable special medical treatment incentivizes healthcare providers to compete with each other in technological innovation, including cutting-edge equipment and new medical treatment. Unlike the public coverage reimbursed by a government allowance, non-reimbursable items are much more profitable to providers. This is because the allowance usually leaves them with a small profit for each item, but non-reimbursable items follow the specific demands of patients and therefore healthcare providers control its supply and margins at their discretion. To secure (or expand) the demand for non-reimbursable items, hospitals have to reinvest profits into new and experimental medical technologies and equipment.

The other Korean policy that may benefit the UK is widening the public's choice of medical services, thereby promoting 
internal competition within the system. Individual choices would eventually reflect popular demands and preferences thereby indicating the necessary quantities to be supplied of certain products/treatments. In that sense, this second approach encourages greater internal competition between healthcare providers to meet the diverse needs of patients. The providers here would have no choice but to provide the most appropriate services and best treatments available to attract customers. Under the internal market policy introduced in 1991 on health reform, the UK's healthcare system distinguishes between purchasers and suppliers of medical equipment and supplies (Propper et al., 2004; Propper et al., 2008). This triggers competition between suppliers to some degree. However, limitations remain because a patient is not classified as a purchaser and thus demand cannot be controlled/predicted. In Korea, however, a patient can choose healthcare providers and services along with cutting-edge medical equipment and new medical treatment (e.g., robot surgery or AIbased diagnosis), which falls under the category of non-reimbursable, as well as special medical treatment not covered by the system. This arrangement prompts healthcare providers to engage in fierce competition to deliver better patient services. For example, large healthcare providers compete with each other to induce greater patient inflows and strive to establish a leading position by providing better customer service and cutting-edge technology. Local hospitals and small clinics then introduce unique and patient-tailored healthcare services, such as integration with traditional oriental medical treatments and acupuncture, to compete against large providers. The vast array of new medical equipment such as CT, MRI, and ECMO equipment, as well as mechanical invasive ventilators to be made available in Korea, explains the efforts made by hospitals to meet patients' needs.

The above two measures designed to expand internal competition should however be utilized under a central authority's thorough supervision and control in order to minimize the possibility of undermining universal health coverage in the UK. This does not mean that the UK government should assume 'full' control over them or abandon incentive mechanisms already in place within the healthcare system (Gaynor et al., 2012). It rather means that a healthcare system should balance public service provision and the incentives of healthcare providers while meeting the demands of citizens and evolving with political, economic, and societal changes. First, a government or a healthcare authority should negotiate prices for various medical services (both non-reimbursable special and regular medical treatments) with healthcare providers (Le Grand, 1999). It is the responsibility of the government to identify and mark the line between a reasonable price and an appropriate quality of health service. Second, a government's safeguarding infrastructure or system should be well set before encouraging the expansion of internal competition. Moreover, it should continue to evolve according to demands and changes as they arise. For example, a patient referral system, as well as a frequent review of non-reimbursable treatments, should be strictly applied to minimize unnecessary healthcare services and overtreatment. Third, a government should provide open and precise information on doctors, clinics, and hospitals to assist a patient in their selection process. After all, rational choice is an underlying enabler of healthy competition between healthcare providers.

\section{Conclusion}

By expanding internal competition, which was already introduced to the UK's healthcare system in 1991, specifically by allowing non-reimbursable special medical treatments and widening public choice of medical services, the UK would be better equipped to respond to a sudden healthcare crisis with (1) appropriate medical equipment and technologies along with the necessary human resources to respond to the sudden pandemic and (2) flexible policy options incentivizing healthcare providers and inducing cooperation from the public in a time of national crisis. The underlying implication of internal competition is a sharing of decision-making powers and responsibilities with societal and private sectors by facilitating participation at all levels. The UK's healthcare system allows a state actor to make all decisions and assume all responsibilities with respect to policy, finance, and services. However, in Korea, a state actor shares decision-making powers and responsibilities with societal and private actors. Instead of being a total healthcare service provider, the Korean healthcare authority is more of a regulating observer. Both societal and private actors should participate in decisions with regard to the benefits, prices, and standards of healthcare services and share responsibility for a healthy medical system. Fighting against COVID-19 is seen as 'all-out-war.'. Providing there is thorough supervision and precise control on the part of the UK government, now is the right time for the entirety of society including patients, private parties, and citizens to engage in this fight together, instead of relying too heavily on their government.

The above analysis signals that the COVID-19 pandemic represents a critical juncture at which the UK's healthcare system could and perhaps should be changed. The new proposed changes, if implemented, could serve as an example to follow for other countries pursuing universal healthcare coverage under the 2030 Agenda for Sustainable Development and could also provide valuable lessons as to how such coverage can be realized in each country according to its national and local context (Webb, 2019). Moreover, if adequate changes are indeed made, nurses, doctors, and other healthcare personnel would no longer assume most of the responsibility for the ongoing crisis. Moreover, a crisis ultimately makes a system and people stronger. The UK's reputable healthcare system, the largest in the world with a long history, should therefore be reformed accordingly.

Nevertheless, it should be borne in mind that internal competition in the Korean healthcare system has also triggered some problems. First, the unnecessary inclusion of non-reimbursable special medical treatments increased 'out-of-pocket' payments for patients, thereby imposing a greater financial burden on Korean society. Specifically, this problem emanates from hospitals charging more for a new treatment that uses cutting-edge medical equipment in order to cover its investment. Second, internal competition has caused an inflow of healthcare services, the clinical effectiveness of which has yet to be verified. Hospitals have persuaded patients to use such services by presenting them as mandatory medical treatment. Because patients are not fully aware of what a service entails or why it is available, they will accept and pay for treatments or services if they are recommended by their doctor. Third, increased internal competition has led certain medical departments such as cosmetic and plastic surgery, whose main profit comes from non-reimbursable special medical treatment, to become more popular than other more general but necessary surgical departments. Fourth, a patient is now more inclined to seek and accept treatment by a large healthcare provider instead of a relatively small-sized provider. This can lead to an imbalance in the quality of healthcare services obtained between large hospitals and local alternatives in terms of monetary benefits, information on disease outbreaks, and patients' medical records. So far, the supervision and control of the Korean government and healthcare authority have helped to minimize these drawbacks emerging from increasing internal competition in its healthcare system. 
Importantly, this article's argument and its comparative structure have some limitations. First, it is too early to definitively characterize the suggested approaches as 'evidence-based,' After all, this article is geared toward stimulating dialog between scholars and practitioners in the healthcare administration community with 'promising' or 'best' practices (Jennings and Hall, 2012). This article, therefore, serves as a critical instrument for bridging scholars and practitioners and offers an opportunity to engage the practice community in a novel way to increase the involvement and participation of societal and private sectors. Second, it is necessary to take into account the difference in population between the UK (66.6 million) and Korea (51.6 million), as well as in population density ( 275 people per sq. $\mathrm{km}$ for the UK, and 529 for Korea) and other factors that may have contributed to Korea's so far successful fight against COVID-19 such as leadership, good citizenship, public-private partnership, and tracing and tracking methods. Ultimately, the difference between the UK and Korea with respect to confirmed COVID-19 cases and deaths is stark. Accordingly, the unexpectedly large figures in the UK imply that holistic action is required urgently to ensure that its well-respected healthcare system can prevail against the virus.

\section{Data availability}

All data generated or analyzed during this study are included in this published article.

Received: 28 July 2020; Accepted: 3 February 2021;

Published online: 02 March 2021

\section{References}

AlKetbi R, AlNuaimi D, AlMulla M, AlTalai N, Samir M, Kumar N, AlBastaki U (2020) Acute myelitis as a neurological complication of Covid-19: a case report and MRI findings. Radiol Case Rep 15(9):1591-1595. https://doi.org/ 10.1016/j.radcr.2020.06.001

Alom S, Haiduc AA, Melamed N, Axiaq A, Harky A (2020) Use of ECMO in Patients With Coronavirus Disease 2019: does the evidence suffice? [published online ahead of print, 2020 Jul 30]. J Cardiothorac Vasc Anesth 2020: S1053-0770(20)30743-6. https://doi.org/10.1053/j.jvca.2020.07.070

Aragão MDFVV, Leal MC, Cartaxo FOQ, Fonseca TM, Valença MM (2020) Anosmia in COVID-19 associated with injury to the olfactory bulbs evident on MRI. AJNR Am J Neuroradiol 41(9):1703-1706. https://doi.org/10.3174/ ajnr.A6675

Ashworth J (2020) Labour calls for plan to clear NHS backlog as new analysis shows Covid-19 response causing huge delays for vital scans and diagnostic tests. The Labour Party. https://labour.org.uk/press/labour-calls-for-plan-toclear-nhs-backlog-as-new-analysis-shows-covid-19-response-causing-hugedelays-for-vital-scans-and-diagnostic-tests/. Accessed 18 Nov. 2020

Battilana J (2011) The enabling role of social position in diverging from the institutional status Quo: evidence from the UK National Health Service. Organ Sci 22(4):817-834. https://doi.org/10.1287/orsc.1100.0574

Bernheim A, Mei X, Huang M, Yang Y, Fayad ZA, Zhang N, Diao K, Lin B, Zhu X, Li K, Li S, Shan H, Jacobi A, Chung M (2020) Chest CT findings in coronavirus disease-19 (COVID-19): relationship to duration of infection. Radio. 200463. https://doi.org/10.1148/radiol.2020200463

Birkinshaw J (2001) Strategies for managing internal competition. Calif Manage Rev 44(1):21-38. https://doi.org/10.2307/41166109

Böhm K, Schmid A, Götze R, Landwehr C, Rothgang H (2013) Five types of OECD healthcare systems: empirical results of a deductive classification. Health Policy 113(3):258-269. https://doi.org/10.1016/j.healthpol.2013.09.003

Capoccia G, Kelemen RD (2007) The study of critical junctures: theory, narrative, and counterfactuals in historical institutionalism. World Polit 59(3):341-369. https://doi.org/10.1017/S0043887100020852

Davie HTO, Nutley SM (2000) Developing learning organisations in the new NHS. BMJ 320(7240):998. https://doi.org/10.1136/bmj.320.7240.998

Department for Business (2020) Check if you're eligible for the coronavirus Small Business Grant Fund. GOV.UK. https://www.gov.uk/guidance/check-ifyoure-eligible-for-the-coronavirus-small-business-grant-fund. Accessed 28 July 2020

Esping-Andersen G (1990) The three worlds of welfare capitalism. Princeton University Press, Princeton
Farace D, Schöpfel J (2010) Grey literature in library and information studies. De Gruyter Saur, Berlin and New York

Fang Y, Zhang H, Xie J, Lin M, Ying L, Pang P, Ji W (2020) Sensitivity of chest CT for COVID-19: comparison to RT-PCR. Radio 200432. https://doi.org/ 10.1148/radiol.2020200432

Favin M, Steinglass R, Fields R, Banerjee K, Sawhney M (2012) Why children are not vaccinated: a review of the grey literature. Int Health 4(4):229-238. https://doi.org/10.1016/j.inhe.2012.07.004

Fougere G (2001) Transforming health sectors: new logics of organizing in the New Zealand health system. Soc Sci Med 52(8):1233-1242. https://doi.org/ 10.1016/S0277-9536(00)00242-2

Garousi V, Felderer M, Mäntylä MV (2016) The need for multivocal literature reviews in software engineering: complementing systematic literature reviews with grey literature. In: Beecham S (ed.) Proceedings of the 20th International Conference on Evaluation and Assessment in Software Engineering, Limerick, Ireland

Gaynor M, Moreno-Serra R, Propper C (2012) Can competition improve outcomes in UK health care? Lessons from the past two decades. J Health Serv Res Policy 17(1_suppl):49-54. https://doi.org/10.1258/jhsrp.2011.011019

Heo K, Lee D, Seo Y, Choi (2020) Searching for digital technologies in containment and mitigation strategies: experience from South Korea COVID-19. Ann Glob Health 86(1):109. https://doi.org/10.5334/aogh.2993

HM Revenue and Customs (2020) Deferral of VAT payments due to coronavirus (COVID-19). https://www.gov.uk/guidance/deferral-of-vat-payments-dueto-coronavirus-covid-19. Accessed 28 July 2020

Janoski T, Hicks AM (1994) The comparative political economy of the welfare state. Cambridge University Press, Cambridge

Jennings Jr ET, Hall JL (2012) Evidence-based practice and the use of information in state agency decision making. J Public Adm Res Theory 22(2):245-266. https://doi.org/10.1093/jopart/mur040

Jenrick R (2020) Government confirms $\mathfrak{E 5 0 0}$ million hardship fund will provide council tax relief for vulnerable households. GOV.UK. https://www.gov.uk/ government/news/government-confirms-500-million-hardship-fund-willprovide-council-tax-relief-for-vulnerable-households. Accessed 28 July 2020

Kooraki S, Hosseiny M, Raman SS, Myers L, Gholamrezanezhad A (2020) Coronavirus disease 2019 (COVID-19) precautions: what the MRI suite should know. J Am Coll Radiol 17(7):830. https://doi.org/10.1016/j.jacr.2020.05.018

Kremer S, Lersy F, de Sèze J, Ferré JC, Maamar A, Carsin-Nicol B, Collange O, Bonneville F, Adam G, Martin-Blondel G, Rafiq M, Geeraerts T, Delamarre L, Grand S, Krainik A (2020) Brain MRI findings in severe COVID-19: a retrospective observational study. Radio 202222. https://doi.org/10.1148/ radiol.2020202222

Kümpers S, Mur I, Maarse H, Van Raak A (2005) A comparative study of dementia care in England and the Netherlands using Neo-Institutionalist Perspectives. Qual Health Res 15(9):1199-1230. https://doi.org/10.1177/ 1049732305276730

Kwon S (2008) Thirty years of national health insurance in South Korea: lessons for achieving universal health care coverage. Health Policy Plan 24(1):63-71. https://doi.org/10.1093/heapol/czn037

Majeed A, Seo Y, Heo K, Lee D (2020) Can the UK emulate the South Korean approach to covid-19? BMJ 369:m2084. https://doi.org/10.1136/bmj.m2084

Lee D, Heo K, Seo Y (2020) COVID-19 in South Korea: lessons for developing countries. World Development 105057. https://doi.org/10.1016/j. worlddev.2020.105057

Le Grand J (1999) Competition, Cooperation, Or Control? Tales From The British National Health Service. Health Aff 18(3):27-39. https://doi.org/10.1377/ hlthaff.18.3.27

Mahood Q, Van Eerd D, Irvin E (2014) Searching for grey literature for systematic reviews: challenges and benefits. Res. Synth. Methods 5(3):221-234. https:// doi.org/10.1002/jrsm.1106

Navarro V (1989) Why some countries have national health insurance, others have national health services, and the U.S. has neither. Soc Sci Med 28(9):887-898. https://doi.org/10.1016/0277-9536(89)90313-4

Park S, Kim YM, Yi S, Lee S, Na BJ, Kim CB, et al. (2020) Coronavirus Disease Outbreak in Call Center, South Korea. Emerging Infect Dis 26(8). https://doi. org/10.3201/eid2608.201274

Petersen K, Feldt R, Mujtaba S, Mattsson M (2008) Systematic mapping studies in software engineering. In: Visaggio G, Baldassarre MT (ed.) Proceedings of the 12th International Conference on Evaluation and Assessment in Software Engineering (EASE), Bari, Italy

Poyiadji N, Shahin G, Noujaim D, Stone M, Patel S, Griffith B (2020) COVID19-associated acute hemorrhagic necrotizing encephalopathy: CT and MRI features. Radio 201187. https://doi.org/10.1148/radiol.2020201187

Propper C, Burgess S, Gossage D (2008) Competition and quality: evidence from the NHS internal market 1991-9. Econ. J. 118(525):138-170. https://doi.org/ 10.1111/j.1468-0297.2007.02107.x

Propper C, Burgess S, Green K (2004) Does competition between hospitals improve the quality of care?: Hospital death rates and the NHS internal market. J 
Public Econ 88(7-8):1247-1272. https://doi.org/10.1016/S0047-2727(02) 00216-5

Ragin CC (2014) The comparative method: Moving beyond qualitative and quantitative strategies. University of California Press, Berkeley and Los Angeles

Ragin CC, Amoroso LM (eds) (2011) Constructing social research: the unity and diversity of method. Pine Forge Press, Thousand Oaks

Royal Papworth Hospital (2020) ECMO: what is it and how is it supporting the COVID-19 surge? Extracorporeal membrane oxygenation supports people who are in respiratory failure and has been vital during the coronavirus pandemic. Royal Papworth Hospital NHS Foundation Trust. https:// royalpapworth.nhs.uk/our-hospital/latest-news/ecmo-covid19. Accessed 17 Nov. 2020

Salkind NJ (2010) Encyclopedia of research design (Vol. 1). Sage Publication Inc, Thousand Oaks

Scharpf FW (2000) Institutions in comparative policy research. Comp Polit Stud 33 (6-7):762-790. https://doi.org/10.1177/001041400003300604

Shim E, Tariq A, Choi W, Lee Y, Chowell G (2020) Transmission potential and severity of COVID-19 in South Korea. Int J Infect Dis.93:339-344. https:// doi.org/10.1016/j.ijid.2020.03.031

Shin YS, Yoon KJ, Kim SW, Lim JW, Lee JH, Kim JH (2018) Survey of Health and Medical Personnel. Seoul: Korea Institute for Health Social Affairs, Policy Report 2018-38. https://khima.or.kr/board/board.php?bo_table=01notice\& wr_id $=1386 \&$ page $=3$. Accessed 18 Nov 2020

Soldani J, Tamburri DA, Van Den Heuvel WJ (2018) The pains and gains of microservices: a systematic grey literature review. J Syst Softw 146:215-232. https://doi.org/10.1016/j.jss.2018.09.082

Stempfhuber M, Schaer P, Shen W (2008) Enhancing visibility: Integrating grey literature in the SOWIPORT Information Cycle. In: Dominic JF, Frantzen J (ed.) Proceedings of International Conference on Grey Literature, Antwerp, Belgium

The Government of the Republic of Korea (2020a) Tackling COVID-19 Health, Quarantine and Economic Measures: Korean Experience. https://ecck.eu/wpcontent/uploads/2020/03/Tackling-COVID-19-Health-Quarantine-andEconomic-Measures-of-South-Korea.pdf. Accessed 28 July 2020

The Government of the Republic of Korea (2020b) Flattening the curve on COVID-19: how Korea responded to a pandemic using ICT. https://www. mois.go.kr/eng/bbs/type002/commonSelectBoardArticle. do?bbsId=BBSMSTR_000000000022\&nttId=76748. Accessed 28 July 2020

The Royal College of Radiologists (2020) Clinical radiology UK workforce census 2019 report. London: The Royal College of Radiologists, Ref No. BFCR(20)2. https://www.rcr.ac.uk/system/files/publication/field_publication_files/ clinical-radiology-uk-workforce-census-2019-report.pdf. Accessed 18 Nov. 2020

Thelen K (1999) Historical institutionalism in comparative politics. Annu Rev Polit Sci 2(1):369-404. https://doi.org/10.1146/annurev.polisci.2.1.369

United Nations (1948) The Universal Declaration of Human Rights. https://www. un.org/en/universal-declaration-human-rights/. Accessed 28 July 2020

Van Cauwenberghe E, Maes L, Spittaels H, van Lenthe FJ, Brug J, Oppert JM, De Bourdeaudhuij I (2010) Effectiveness of school-based interventions in Europe to promote healthy nutrition in children and adolescents: systematic review of published and 'grey' literature. Br. J. Nutr. 103(6):781-797. https://doi.org/ $10.1017 /$ S0007114509993370
Web D (2019) Universal Health Coverage for Sustainable Development-Issue Brief. The HIV, Health and Development Group (HHD) of the UNDP Bureau for Policy and Programme, Geneva, Swiss. https://www.undp.org/content/undp/ en/home/librarypage/hiv-aids/universal-healthcoverage-for-sustainabledevelopment-issue-br.html. Accessed 10 Nov 2020

Worldometers (2020) COVID-19 Coronavirus Pandemic. https://www. worldometers.info/coronavirus/\#countries. Accessed 28 July 2020

World Health Organisation (1978) Declaration of Alma-Ata. In: International Conference on Primary Health Care, Alma-Ata, USSR, 6-12 Sep 1978

Xavier A (2003) Hospital competition, GP fundholders and waiting times in the UK internal market: the case of elective surgery. Int J Health Care Finance Econ 3(1):25-51. https://doi.org/10.1023/A:1023219915747

Yoon K (2020) Kolonabaileoseugam-yeomjeung-19 daeeung-eul tonghae salpyeobon gam-yeombyeong-gwa gong-gongbogeon-uilyo. COVID-19 Response to Public Health and Medical Services, Sejong, Korea

\section{Author contributions}

All authors contributed equally to this work. The authors carried out the literature review, collected the data, analyzed it, and wrote the equal portion of the manuscript. The authors contributed to the manuscript revisions. The authors approve of the manuscript and agree to be held accountable for the content presented in the manuscript.

\section{Competing interests}

The authors declare no competing interests.

\section{Additional information}

Correspondence and requests for materials should be addressed to Y.S.

Reprints and permission information is available at http://www.nature.com/reprints

Publisher's note Springer Nature remains neutral with regard to jurisdictional claims in published maps and institutional affiliations

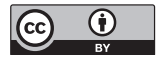

Open Access This article is licensed under a Creative Commons Attribution 4.0 International License, which permits use, sharing, adaptation, distribution and reproduction in any medium or format, as long as you give appropriate credit to the original author(s) and the source, provide a link to the Creative Commons license, and indicate if changes were made. The images or other third party material in this article are included in the article's Creative Commons license, unless indicated otherwise in a credit line to the material. If material is not included in the article's Creative Commons license and your intended use is not permitted by statutory regulation or exceeds the permitted use, you will need to obtain permission directly from the copyright holder. To view a copy of this license, visit http://creativecommons.org/ licenses/by/4.0/.

(C) The Author(s) 2021 